\title{
RELATO DE EXPERIÊNCIA DE ESTÁGIO PROFISSIONALIZANTE EM UMA ENFERMARIA PSIQUIÁTRICA DE UM HOSPITAL GERAL
}

\section{Report on professionalism stage experience in a psychiatric nursery of a general hospital}

Camila Fernandes Troina - UFU/Brasil

RESUMO: O artigo em questão refere-se à experiência de um estágio profissionalizante em psicologia, realizado na enfermaria psiquiátrica de um hospital geral e tem como objetivo demonstrar como a experiência de um estágio pode estar relacionada com um melhor preparo do profissional de psicologia e das possibilidades de atuação na área da saúde mental, indo contra os padrões hegemônicos de formações voltadas para atuação profissional em consultório particular. Para isso, foi feita uma descrição das atividades realizadas, levantamento dos aspectos importantes que suscitaram a partir da prática e análise das reverberações produzidas nesse estágio em questão no desenvolvimento do profissional psi. A partir desses aspectos pode-se notar a importância que o estágio teve em possibilitar o aprimoramento de conhecimentos e manejos técnicos a partir de estudos e das práticas, contribuindo assim para uma formação e atuação profissional de forma ampliada, auxiliando em um melhor desempenho e na inserção do psicólogo em campos relacionados a saúde mental.

Palavras-chave: Atuação profissional; Estágio; Formação profissional; Saúde mental.

ABSTRACT: The work in question refers to the experience of a professional internship in psychology, performed in the psychiatric ward of a general hospital and aims to demonstrate how the experience of an internship can be related to a better preparation of the psychology professional and the possibilities of performance in the area of mental health, going against the hegemonic patterns of training aimed at professional work in private practice. For this, a description of the activites carried out was made, a survey of the important aspects that emerged from the practice and analysis of the reverberations produced at this internship in the development of the psi professional. From these aspects it is possible to notice the importance that the internship has had in enabling the improvement of knowledge and technical management from studies and practices, thus contributing to a professional formation and performance in an expanded way, assisting in a better performance and the insertion of the psychologist in fields related to mental health.

Keywords: Internship; Mental health; Professional performance; Professional qualification.

\section{INTRODUÇÃO}

Educação, Psicologia e Interfaces, Volume 2, Número 3, p. 82-91, Setembro/Dezembro, 2018.

ISSN: 2594-5343. DOI: https://doi.org/10.37444/issn-2594-5343.v2i3.91 
Relato de experiência de estágio profissionalizante em uma enfermaria psiquiátrica de um hospital geral

A partir das ações integradas de saúde na década de 80, que mais tarde daria origem ao Sistema Único de Saúde, iniciou-se um processo de expansão da rede ambulatorial em saúde com equipes multiprofissionais nas quais foram também incluídos os profissionais da psicologia trazendo assim, novos desafios e campos de atuação na participação da assistência em saúde mental (Vasconcelos, 2004). Apesar dessa inserção e consequentemente valorização do trabalho dos profissionais de psicologia, autores como Lancetti (1993), Vasconcelos (2004) e Neto (2010), denunciam o despreparo destes profissionais e as poucas repercussões temáticas da saúde mental na formação dos psicólogos, que vem repetindo os padrões hegemônicos de uma formação voltada para atuação em consultórios particulares.

Neste sentido, o trabalho em questão visa dar visibilidade a essa lacuna tão importante que é a formação do profissional e as possibilidades de atuação na área da saúde mental, através do relato de experiência de um estágio profissionalizante em Psicologia, realizado na enfermaria psiquiátrica de um hospital geral. O estágio em questão teve como direcionamento a prestação de atendimento a pessoas em sofrimento psíquico grave e seus familiares a partir da perspectiva da Rede de Atenção Psicossocial e tendo como embasamento os conceitos de vínculo, acolhimento e co-responsabilização pelo cuidado e equipe multiprofissional. Para isso, foi preciso compreender a importância da situação do psicólogo junto ao público-alvo; Planejar, desenvolver e avaliar estratégias de intervenção em saúde em contextos grupais; Realizar intervenções em equipe multiprofissional; Realizar acolhimento a usuários e familiares.

Afim de atingir tais objetivos, buscamos auxilio e apoio teórico com foco em saúde mental, perpassando por vários aspectos conforme fosse surgindo a necessidade, como grupos e grupalidade, acolhimento, oficinas expressivas, sexualidade de usuários da saúde mental e ainda alguns conceitos psicanalíticos como a função continente e o uso da contratransferência.

\section{MATERIAL E MÉTODO}

Trata-se de um relato de experiência de um estágio profissionalizante em Psicologia, realizado na enfermaria psiquiátrica de um hospital geral. Para isso, foi feita uma descrição das atividades realizadas, levantamento dos aspectos importantes que 
suscitaram a partir da prática e análise das reverberações produzidas nesse estágio em questão para a formação profissional.

\section{RESULTADOS E DISCUSSÃO}

As atividades desenvolvidas nesse estágio foram diversas como: Leitura de textos, visitas ao Hospital Geral, visita ao CAPS, participação em gestões de caso, preparação e coordenação de oficinas e rodas de conversa, preenchimentos e leituras de prontuário redação dos relatórios diários, aula de psicofarmacologia, acolhimento, orientações e supervisões de grupo.

A atividade de leitura de textos foi algo continuo durante todo o estágio, tanto no que se refere ao preparo para as outras atividades como também para compreender alguns fenômenos que se destacavam em nossas experiências. As visitas ao Hospital Geral e ao CAPS, antes e durante o início das realizações de oficinas, foram realizadas para que pudéssemos conhecer a equipe, o espaço e minimamente o funcionamento destes dispositivos da rede. Nas gestões de caso, que visavam uma discussão multidisciplinar sobre usuários do serviço da enfermaria psiquiátrica, buscávamos compreender o percurso que o usuário do serviço de saúde em questão havia percorrido pelos dispositivos da rede, bem como a eficácia ou deficiências de tais dispositivos, já as orientações e supervisões de grupo aconteciam afim de poder acolher o que era mobilizado durante as outras atividades, além de trazer um aporte teórico a partir de tais aspectos e acolher quaisquer angústias que pudessem surgir ao longo do estágio.

Neste sentido, um ponto importante de reflexão são os serviços de saúde, que Merhy (2002) nos dá suporte teórico para pensa-los como palco da ação de um time de atores, que têm intencionalidade em suas ações e que disputam o sentido geral do trabalho. Sendo assim, estes times atuam fazendo uma mistura, nem sempre evidente, entre seus territórios privados de ação e o processo público de trabalho. O cotidiano, portanto, tem duas faces: a das normas e papéis institucionais e a das práticas privadas de cada trabalhador.

Antes das atividades coordenadas pelos estagiários, sendo primeiramente oficinas de expressão livre e depois as rodas de conversa, ocorria a preparação das mesmas. Nas oficinas eram organizados materiais e também o local que era por sua vez escolhido em comum acordo com os usuários do serviço de saúde, nelas foram possíveis trabalhar com 
Relato de experiência de estágio profissionalizante em uma enfermaria psiquiátrica de um hospital geral

argila, desenho livre, produção de máscaras no papel com lápis de cor e tintas, grupo de sentidos atribuídos a internação na psiquiatria, entre outros. Neste sentido Nise da Silveira (citado por Lima, 2012), uma renomada médica psiquiatra alagoana, responsável pela criação do Museu de Imagens do Inconsciente na década de 1950, afirmava que a expressão livre permitia um acesso mais fácil ao mundo interno dos paciente, entendendo suas produções como algo que vai muito além das representações distorcidas de conteúdos pessoais reprimidos ou mero reflexos de sintomas, mas que a partir de tais atividades o indivíduo pode expressar a si mesmo e ir além, criando algo novo, produzindo símbolos com efeitos de transformação tanto de sua realidade psíquica como também na realidade compartilhada. Sendo assim, a produção de sua expressão permite novas maneiras de compartilhar a si mesmo, sua própria subjetividade, que as vezes pode ser tão difícil de ser colocada em palavras.

A relação que surge através de atividades de expressão livre são então entre a arte, um inconsciente produtivo e um corpo em permanente autopoiésis, que se refere a capacidade dos seres vivos de produzirem a si próprios, onde cada sujeito pode construir algo ímpar e expor a si mesmo e ao seu próprio sofrimento, com a potência de provocar mutações subjetivas, ampliar a sensibilidade e potencializar a vida (Lima 2012).

Com o decorrer das oficinas de expressão livre, os próprios usuários passaram a demandar modificações nesse formato, demonstrando necessidade de falar, ouvir e compartilhar experiências. Neste sentido, buscando ir de encontro com as demandas e com a possibilidade de buscar atividades que auxiliassem no fortalecimento e criação de novos vínculos e identificações, foi pensado o formato das rodas de conversa. Nesse novo formato eram pensados temas que chamassem a atenção desses usuários, o que era observado nas atividades anteriores ou perguntado a cada um sobre o que gostariam de falar. A partir disso, foram pensados e utilizados disparadores artísticos como animações, músicas e figuras para trabalhar as temáticas, que a saber foram: a experiência a respeito da internação psiquiátrica; aspectos da infância; relações familiares; ganhos e perdas em experiências pessoais; relações interpessoais; recursos internos e autocuidado. Um dos cuidados que tivemos nessas novas propostas foi de não infantilizar os pacientes, colocando-os no lugar de portadores das próprias palavras e reflexões, de forma a valorizar suas próprias produções. 
Essa mudança das oficinas foi muito interessante, uma vez que passaram a assumir uma posição mais ativa, de fala, de compartilhamento das suas próprias vivências, de maior interesse e demandar, nos surpreendemos com as reflexões profundas que traziam juntamente com colocações muito importantes sobre aspectos do adoecimento, das redes de apoio que possuem ou não, dos medos e anseios, das expectativas sobre o futuro, entre muitas outras coisas que foram suscitando no grupo.

De acordo com Bechelli e Santos (2005), as atividades em grupo são importantes e potencializadoras uma vez que nelas algumas pessoas podem expressar sentimentos que outras jamais ousaram em expressar; experiências e sentimentos que muitos achavam ser individuais podem ser vividos e manifestados em grupo; a troca de conhecimento e sentimento permite uma maior auto aceitação.

Dentro dessa perspectiva, a roda de conversa se fundamenta como oficina de intervenção onde há espaço para reflexões entre seus participantes a respeito de várias temáticas que possam ir surgindo de acordo com a configuração própria de cada grupo. Segundo Costa, Bosco Filho, Medeiros e Silva (2015), esse modelo surge como uma metodologia importante que trabalha em grupo a maior autonomia dos sujeitos, proporciona uma maior comunicação e fortalecimento dos mesmos e uma maior capacidade nas pessoas em resolver conflitos. Podendo desta forma contribuir para uma redução do sofrimento psíquico decorrentes de conflitos, dúvidas e incertezas relacionadas ao viver em sociedade.

Após as oficinas e rodas de conversas também eram realizados os preenchimentos e leituras de prontuário, destacando pontos importantes sobre a atuação do paciente no grupo sem exposição de aspectos pessoais e privados. Assim como os prontuários, também eram realizados a redação dos relatórios diários após cada atividade de gestão de caso, oficina, roda de conversa e a aula de psicofarmacologia básica que foram realizadas a partir da necessidade que os estagiários se depararam em compreender melhor efeitos e funcionalidades dos fármacos.

Ainda neste contexto, foi necessário a realização de acolhimentos de forma pontual com pacientes que demandavam uma atenção mais individual. Neste sentido vale a pena refletir sobre o conceito de desamparo, aspecto fundamental do sujeito humano. Silva (2013) pontua a primeira situação de desamparo como modelo de inúmeras outras a quais todo sujeito se confronta no decorrer de sua existência, repetindo em suas 
Relato de experiência de estágio profissionalizante em uma enfermaria psiquiátrica de um hospital geral

vivencias e situações posteriores, retornando de diversas formas de angústia e separação. São nessas experiências de desamparo que o sujeito depara-se com algo mais íntimo de sua singularidade, na mais crua solidão, daí a necessidade e importância da continência e do holding, funções que também são exercidas por nós psicoterapeutas, possibilitando assim ferramentas que mais tarde podem ser internalizadas auxiliando no suporte de angústias e conflitos. Dessa forma, quando o sujeito de alguma forma não dá mais conta de suas angústias entra a crise, um momento em que o corpo grita que daquela forma não dá e reclama mudanças. Podemos pensar então o conceito-ferramenta de "holding", que se defini por um ambiente suficientemente-bom, com estabilidade, confiança e acolhimento, propiciando assim um espaço terapêutico.

Vale ainda pontuar o entendimento de acolhimento, outro aspecto importante da função do psicoterapeuta em qualquer lugar em que ela seja exercida, sendo compreendido como uma postura do profissional de receber, escutar e tratar de forma humanizada o paciente e suas demandas, que auxilia também na construção de vinculo, além de garantir, nos serviços de saúde, acesso com responsabilização e resolutividade. Sendo assim, acolhimento é aqui compreendido como algo que não limitasse apenas a um processo de triagem, mas uma forma de estar com pessoas, se disponibilizando corporalmente e afetivamente, exercendo assim a função de continência já descrita anteriormente (SCHEIBEL; FERREIRA, 2011).

Apesar das dificuldades que foram sendo sentidas ao longo do estágio como, a diferença entre membros da equipe, descontinuidades dos serviços, falhas nas comunicações, rotatividade dos usuários do serviço, falta de verbas, faltas de serviços como unidades de acolhimento para adultos, falta de respeito ao fluxo de utilização dos dispositivos da rede de saúde, entre outros, foi a primeira oportunidade em trabalhar, de forma a ir de encontro com a linha de cuidado em sua forma mais ampla.

A linha de cuidados, segundo Cecílio e Merhy (2003), atravessa inúmeros serviços de saúde em um circuito para que o indivíduo possa obter a integralidade que necessita, no sentido de compreender a condição integral do ser humano, atendendo à demandas e necessidades de cada pessoa "com um conjunto articulado e contínuo de ações e serviços preventivos e curativos, individuais e coletivos, exigidos para cada caso em todos os níveis de complexidade" (Brasil, lei no 8.080 ), sendo este um dos princípios assegurados pelo SUS (Sistema Único de Saúde).Neste sentido, visa a integralidade do sujeito que a

Educação, Psicologia e Interfaces, Volume 2, Número 3, p. 82-91, Setembro/Dezembro, 2018. 
equipe trabalha, afim de buscar não só sanar exclusivamente um sintoma, mas compreender a história de vida daquela pessoa e do seu meio, buscando a promoção da saúde para ela e para seus familiares, atravessando também as questões sociais também estão implicadas. Isso ficava evidente nas gestões de caso, onde vários profissionais das áreas de assistência social, enfermagem, psicologia e medicina, se uniam para poder discutir sobre várias questões de um paciente, como por exemplo como ele chegou na rede, como que foi esse percurso na rede, pra onde ele vai depois da alta, benefícios que recebe ou deixa de receber, rede de apoio que tem ou deixa de ter, enfim, muitos detalhes que possibilitam uma visão mais complexa e profunda de alguém, não limitando-se a compreender, medicar e extinguir apenas um sintoma, mas de fazer essa leitura mais especifica sobre cada caso.

Durante os espaços de supervisão e orientações pudemos adentrar em alguns temas que foram chamando mais atenção como por exemplo a sexualidade dos pacientes da saúde mental e a relação disso com a descontinuidade do tratamento medicamentoso uma vez que os medicamentos podem e causam com frequência de disfunções sexuais. Ainda com relação à sexualidade um dos pontos que pudemos discutir durante este estágio foi a expressão da sexualidade dos pacientes na internação, algo que aparecia e era rapidamente reprimido pela equipe, porém sem abrir uma discussão sobre o fato do espaço da enfermaria de psiquiatria ser mista. Neste sentido Vacanti e Caramelli (2005) salientam a importância da atividade sexual como um componente da qualidade de vida, relacionada até mesmo com a longevidade. Possas, Simão, Delgado, Galbinski e Sá (2008) destacam a perspectiva dos direitos humanos, em que a sexualidade deveria ser encarada como algo saudável e desejável, sendo que a diversidade deveria ser algo aceito e respeitado. Neste sentido Detomini, Rasera e Peres (2016) ressaltam que, de acordo com o Ministério da Saúde, as políticas públicas referentes à saúde mental estabelecem que os usuários devem ser protegidos de qualquer espécie de discriminação associada à sua condição. Detomini et al (2016) destacam ainda a pouca visibilidade sobre o tema, uma vez que há poucos estudos sobre as ações negativas que os psicofármacos têm na vida sexual dos usuários com transtornos mentais graves.

Outro aspecto importante observado durante o estágio foi a desconstrução da compreensão equivocada das estruturas psíquicas instituídas pela psicanalise como neurose, psicose e perversão. Durante muito tempo de minha graduação, imaginava uma 
Relato de experiência de estágio profissionalizante em uma enfermaria psiquiátrica de um hospital geral

forma hierarquizada de estruturas, onde a neurose era a saudável e as outras adoecidas, porém com o estágio pude perceber que são apenas modos de existir, cada com seus limites e potencialidades, cada qual com seus aspectos saudáveis e adoecidos. Foi de suma importância passar a compreender na prática os aspectos saudáveis do funcionamento psíquico que pode ser erroneamente interpretado como adoecimento. Um desses casos é o próprio delírio que assim como outro sintoma como a própria febre, denuncia que algo não está bem com o sujeito, mas que ao mesmo tempo é uma resposta a tudo isso que por vezes provoca uma restruturação da dinâmica familiar e até mesmo como uma tentativa de reconstrução de uma realidade difícil de suportar (Freud, 1924). Importante então perceber que o corpo fala de várias formas e que se faz necessário aprender a ouvirmos o que ele quer dizer.

\section{CONSIDERAÇÕES FINAIS}

O estágio em questão possibilitou a vivência de novas experiências, aprimorando os conhecimentos e manejos técnicos a partir de estudos e das práticas, contribuindo assim para formação e atuação profissional de forma ampliada, auxiliando em um melhor desempenho na atuação profissional em campos relacionados a saúde mental, através dos contatos obtidos no estágio com os dispositivos, profissionais e usuários da rede de saúde mental.

ExperiÊncias como esta, que colocam o estagiário em contato direto nas frentes de elaboração e coordenação de atividades, bem como na participação de gestões de caso, possibilitam o desenvolvimento da autonomia como profissional e de recursos para a prática, ampliando assim o seu repertório de possibilidades. Além de tais aspectos, as supervisões e orientações auxiliaram no aporte teórico que possibilitasse a fundamentação teórica para as atividades desenvolvidas, suscitando questionamentos e funcionando também como norteadores para a atuação. Esses espaços também são de grande importância para sustentar as angústias do profissional em formação em seus primeiros contatos, promovendo ensinamentos e desenvolvimentos de habilidades importantes para profissão de forma crítica e respeitosa tanto no que se refere ao funcionamento da rede e de seus dispositivos como também no próprio manejo com o paciente, clarificando assim a importância de experiências como essas que possam auxiliar em uma melhor formação desses profissionais da área psi.

Educação, Psicologia e Interfaces, Volume 2, Número 3, p. 82-91, Setembro/Dezembro, 2018. 


\section{REFERÊNCIAS BIBLIOGRÁFICAS}

BRASIL, Governo Federal; BRASIL. Lei no 8.080, de 19 de setembro de 1990. Dispõe sobre as condições para a promoção, proteção e recuperação da saúde, a organização eo funcionamento dos serviços correspondentes e dá outras providências. Diário Oficial da união, v. 20, 1990.

CECILIO, Luiz Carlos de Oliveira; MERHY, Emerson Elias. A integralidade do cuidado como eixo da gestão hospitalar. Construção da integralidade: cotidiano, saberes e práticas em saúde, v. 1, p. 197-210, 2003.

DETOMINI, Vitor Corrêa; RASERA, Emerson Fernando; PERES, Rodrigo Sanches. Sexualidade e saúde mental: vivências, serviços e estigmas. Revista da SPAGESP, v. 17, n. 2, 2016.

FREUD, Sigmund. Edição standard brasileira das obras psicológicas completas de Sigmund Freud. Imago Editora, 2016.

LIMA, Elizabeth Araújo. Artes menores: criação de si e de mundos nas ações em saúde mental. Saúde mental e arte: práticas, saberes e debates. São Paulo: Zagodoni, p. 39-52, 2012.

MACEDO, Carina Rugai Moreira de. A função continente e o uso da contratransferência como instrumentos na psicoterapia de grupo com pacientes com severas pertubações no desenvolvimento do psiquismo. Vínculo, v. 7, n. 2, p. 16-23, 2010 .

MERHY, Emerson Elias. Saúde: a cartografia do trabalho vivo. In: Saúde: a cartografia do trabalho vivo. 2002.

DE ALBUQUERQUE POSSAS, Cristina et al. àS IST/HIV/AIDS NOS SERVIÇOS DE SAÚDE MENTAL NO BRASIL. PREVENÇÃO E ATENÇÃO ÀS IST/AIDS NA SAÚDE MENTAL NO BRASIL, p. 13, 2008.

SCHEIBEL, Aline; HECKER FERREIRA, Lígia. Acolhimento no CAPS: reflexões acerca da assistência em saúde mental. Revista Baiana de Saúde Pública, v. 35, n. 4, p. 966, 2012.

SILVA, Mariana Bassoi Duarte da. O sofrimento psíquico do sujeito em condição de estrangeiro. 2016.

VACANTI, Luciano Janussi; CARAMELLI, Bruno. Idade e distúrbios psicológicos. Variáveis associadas à disfunção sexual no período pós-infarto. Arquivos Brasileiros de Cardiologia, v. 85, n. 2, p. 10-14, 2005.

LANCETTI, Antonio. Clínica grupal com psicóticos: a grupalidade que os especialistas näo entendem. In: Saúdeloucura, 4. 1993. p. 155-71. 
Relato de experiência de estágio profissionalizante em uma enfermaria psiquiátrica de um hospital geral

NETO, Ferreira; LEITE, João. A atuação do psicólogo no SUS: análise de alguns impasses. Psicologia: ciência e profissão, v. 30, n. 2, p. 390-403, 2010.

VASCONCELOS, Eduardo Mourão. Mundos paralelos, até quando? Os psicólogos e o campo da saúde mental pública no Brasil nas duas últimas décadas. Mnemosine, 2004.

BECHELLI, Luiz Paulo de C.; DOS SANTOS, Manoel Antônio. O paciente na psicoterapia de grupo. Revista Latino-Americana de Enfermagem, v. 13, n. 1, 2005.

COSTA, Raphael Raniere de Oliveira et al. As rodas de conversas como espaço de cuidado e promoção da saúde mental. Revista de Atenção à Saúde (antiga Rev. Bras. Ciên. Saúde), v. 13, n. 43, 2015.

\section{Credenciais da autora}

TROINA, Camila Fernandes. Graduada em Psicologia pela Universidade Federal de Uberlândia - UFU. E-mail: camilatroina@uol.com.br

Endereço para correspondência: - E-mail: camilatroina@uol.com.br

Como citar este artigo (Formato ABNT): TROINA, Camila Fernandes. Relato de experiência de estágio profissionalizante em uma enfermaria psiquiátrica de um hospital geral. Educação, Psicologia e Interfaces, v.2, n.3, p. 82-91, 2018. DOI: https://doi.org/10.37444/issn-2594-5343.v2i3.91

Recebido: 04/02/2018. Aceito: 26/05/2018 